\title{
АЛГОРИТМ КОММУНИКАТИВНОГО ВЗАИМОДЕЙСТВИЯ В АЛЬТЕРНАТИВНОМ РАЗРЕШЕНИИ ПРАВОВЫХ СПОРОВ И КОНФЛИКТОВ ${ }^{1}$
}

\section{ALGORITHM OF COMMUNICATIVE INTERACTION IN ALTERNATIVE RESOLUTION OF LEGAL DISPUTES AND CONFLICTS}

\section{E. Usmanova \\ P. Malyshkin}

Summary. The article examines the algorithm of communicative interaction in the alternative resolution of legal disputes and conflicts. It is noted that the algorithm of communicative interaction in the alternative resolution of legal disputes and conflicts is a description of a specific behavioral process aimed at achieving reconciliation of the parties in the form of a sequence of elementary behavioral actions (steps), which includes, along with the actual behavior, also tracking a changing situation, analyzing conditions, at which this action is performed, as well as other characteristics that directly affect the behavior of the parties and mediators in resolving the conflict.

Keywords: legal dispute, conflict, alternative form, mediation communicative interaction, communication algorithm.

\author{
Усманова Елена Фанильевна \\ К.ю.н., дочент, Национальный исследовательский \\ Мордовский государственный университет \\ им. Н.П. Огарева (2. Саранск) \\ Usmanowa_ef@rambler.ru \\ Малышкин Павел Викторович \\ К.ю.н., дочент, Саранский кооперативный \\ институт (филиал) Российского университета \\ кооперации
}

Аннотация. В статье исследуется алгоритм коммуникативного взаимодействия в альтернативном разрешении правовых споров и конфликтов. Отмечается, что алгоритм коммуникативного взаимодействия в альтернативном разрешении правовых споров и конфликтов - это описание конкретного поведенческого процесса, направленного на достижение примирения сторон в виде последовательности элементарных поведенческих действий (шагов), которая включает наряду с собственно поведением ещё и отслеживание меняющейся обстановки, анализ условий, при которых данное действие выполняется, а также другие характеристики, непосредственно оказывающие влияние на поведение сторон и посредников при разрешении конфликта.

Ключевые слова: правовой спор, конфликт, альтернативная форма, медиация коммуникативное взаимодействие, алгоритм коммуникативного взаимодействия.

воречий, который во многих случаях может заменить собой, ввиду своей высокой эффективности и гибкости, традиционные методики урегулирования конфликтных ситуаций. [4] Одним из основных и законодательно урегулированных способов разрешения правовых споров и конфликтов является медиация. Работа по разрешению конфликтной ситуации требует от медиатора подготовки, наделения определенными навыками, к примеру, такими как заблаговременная разработка и принятие мер организационно-правового характера, умение планирования; специальная подготовка, в первую очередь профессиональная, психологическая. Немаловажной деталью «качественной» подготовки медиаторов к работе в кризисных ситуациях является коммуникативная компетентность, ведь ее значимость 
определяется психологической и практической подготовленностью к коммуникативному взаимодействию. Грамотное владение компонентами коммуникативного взаимодействия представляет собой сформированную профессиональную коммуникативную компетентность, которая, при помощи разнообразных знаковых систем, способствует многостороннему общению. Основная роль в таком общении, конечно же, отводится языковым средствам.

Алгоритм коммуникативного взаимодействия в альтернативном разрешении правовых споров и конфликтов - это описание конкретного поведенческого процесса, направленного на достижение примирения сторон в виде последовательности элементарных поведенческих действий (шагов), которая включает наряду с собственно поведением ещё и отслеживание меняющейся обстановки, анализ условий, при которых данное действие выполняется, а также другие характеристики, непосредственно оказывающие влияние на поведение сторон и посредников при разрешении конфликта.

Алгоритм коммуникативного взаимодействия в альтернативном разрешении правовых споров и конфликтов предполагает ряд этапов, среди которых:

- проведение работы по выяснению всей необходимой информации по конфликтной ситуации, ее анализ, общение с каждой стороной в отдельности, с ближайшим окружением и т.д.

- встреча с обеими сторонами и процесс обсуждения причин, методов урегулирования и возможного исхода конфликтной ситуации;

- непосредственное разрешение спорной ситуации.

- оценивание результата.

При этом, в зависимости от психологических особенностей субъектов и ситуации в каждом конкретном поведенческом действии могут применяться различные стратегические и тактические средства.

Эффективность протекания коммуникативного процесса во многом зависима от профессиональных знаний и навыков медиатора. Одной из особенностей коммуникативной компетенции таких сотрудников является психологическая составляющая. Знание психологических особенностей коммуникации характеризует высокий уровень профессиональной компетенции, говорит о высокой степени культуры общения, что впоследствии способствует эффективному процессу коммуникативного взаимодействия.

Самым эффективным вербальным общением являются переговоры лицом к лицу, так как здесь считается наиболее достижим эффект смысловой нагрузки диалога, а также воздействия на собеседника. Во время ведения переговоров, необходимо выстраивать равные отношения, с помощью определенных составляющих, в число которых входят: порядок изложения своих мыслей, работа с голосом (громкость, тембр), четкая и грамотная речь, эмоциональность и мимика лица, использование жестикуляции. Неправильное применение всех этих средств, несомненно, приведет только к ухудшению конфликтной ситуации.

Реализация определенного речевого поведения при альтернативном разрешении правовых споров и конфликтов, во многом зависит от верно выбранных тактических и стратегических приемов, которые в целом включаются в алгоритм коммуникативного взаимодействия. Тем самым правильное разрешение юридического конфликта будет зависеть от выбранной стратегии. Следование правилам речевого поведения, а так же необходимость сохранения и развития культуры речи при разрешении юридических конфликтов определяет важное практическое и теоретическое значение. Использование в конфликте определенной стратегии возможно лишь при помощи различных коммуникативных тактик и ходов. Любая возможная стратегия может быть осуществлена при помощи определенного набора коммуникативных тактик.

Алгоритм коммуникативного взаимодействия в условиях конфликтной ситуации предусматривает различные варианты поведения:

- противодействие, соперничество (человек максимально ориентирован только на собственные интересы, не учитывает интересы другого человека). Борьба отличается от соперничества стилем поведения, в силу того что здесь конфликтующие стороны опираются на авторитет, власть и силу закона. Такую модель можно использовать для защиты своих интересов от посягательства на них другой конфликтующей стороной, так же стоит занять жесткую позицию по отношению к оппоненту, не дать ему использовать манипуляционную технику относительно видимости его авторитета и власти.

- сотрудничество (стратегия сотрудничества основана на высоком уровне оценки собственных интересов и интересов соперника). Данная стратегия основана на признании ценности межличностных отношений между конфликтующими сторонами. В данном случае стороны должны вместе решать возникшие проблемы, а также поддерживать дружественные отношения, в противном случае все приложенные усилия могут обернуться для сторон негативными по- 
следствиями. Если при разрешении конфликта взаимодействие и общение между сторонами разумно, то сотрудничество будет развиваться и протекать эффективно. [2] Само по себе сотрудничество является одной из самых сложных стратегий, потому как требуется решать возникший конфликт только сообща, прикладывать все усилия сторон.

- избегание (человек не преследует своих целей, при этом также отсутствует заинтересованность в целях других людей);

- компромисс (предполагает готовность пожертвовать частью своих интересов, если противоположная сторона поступит так же). Понятия «компромисс» и «консенсус» имеют одинаковые свойства, и они заключаются в том, что данные термины основаны на уступке одного из субъекта конфликта в занятой им позиции. Такая стратегия направлена на сохранение нормальных отношений между конфликтующими субъектами, а также на дальнейшее их развитие после разрешения конфликта. Согласование интересов конфликтующих сторон на новой основе или же, другими словами, «компромисс» основывается на балансе интересов конфликтующих сторон. По-другому данную стратегию можно назвать стратегией взаимной уступки.

- уступчивость (максимальная ориентированность на цели другого человека с пренебрежением к своим). При использовании стратегии «уступки» одна из конфликтующих сторон стремится уйти от конфликта. Значение личных интересов противоположно, чем в предыдущем случае. Так, субъект конфликта высоко оценивает интересы соперника, нежели свои, тем самым жертвуя ими в пользу интересов соперника, при этом одна из сторон конфликта уверена в своей правоте, имеет весомые аргументы относительно предмета спора и точно знает, что соперник не будет оперировать средствами защиты [3].

Речевая культура медиатора, осуществляющего свою деятельность на профессиональной основе, подчиняется определенным нормам, правилам и принципам, которые необходимо соблюдать для успешного проведения согласительной процедуры. Одним из принципов, лежащих в основе практики примирения сторон при разрешении споров между сторонами, является принцип нейтральности. Нейтральность, независимость и беспристрастность посредника - это правило, согласно которому он стремится к равному и справедливому отношению к сторонам в ходе примирения. Важно сохранять беспристрастное отношение к каждой из сторон и обеспечивать им одинаковое право на участие в переговорах. [1]
Вступительное слово посредника, с которого начинается процедура - это «неформальное обращение к сторонам», открывающее сессию процесса урегулирования спора, целью которого является подготовка сторон к переговорам, то есть разъяснение и предвосхищение процесса разрешения конфликта для сторон.

На этапе подготовки сторон к примирительной процедуре специалист информирует о принципе нейтральности и раскрывает его содержание, например: посредник не является судьей, он не принимает решений о том, кто прав, а кто виноват, он лишь оценивает доказательства. Будучи нейтральным, он устраивает переговоры между сторонами конфликта, чтобы те могли говорить все, что считают нужным и могли слышать друг друга. Посредник не заинтересован в ситуации, которая решается в пользу любого из субъектов конфликта.

Вербальные проявления нейтральности наблюдаются и в таких фрагментах речи посредника, которые выражают особые технологические приемы примирения сторон: техника перефразирования, обобщение и развитие идей. Техника перефразирования обычно формируется речевыми формулами: «другими словами», «Я вас правильно понимаю», «вы говорите...», «это так?» и т.д. Собеседник «возвращает» реплику оппонента, не интерпретируя сказанное, сосредоточившись на фактах. Нейтральность проявляется здесь в выделении объективной информации - что на самом деле произошло.

Посредник своим пересказыванием отделяет факты от эмоций и от субъективной интерпретации сторон. Чтобы выявить и отработать эмоции, собеседник использует фразы: «я вижу, что вы сердитесь», «я вижу, что вы его задели», давая понять, что собеседник это услышал.

В то же время при работе с эмоциями посредник не может использовать фразы: «я понимаю ваши чувства / негодование», «я согласен с тем, что вы чувствуете», поскольку они создают впечатление, что он присоединяется к одной из сторон конфликта, что приводит к потере нейтральности посредника, и соответственно недопустимо. Для обозначения толкования сторон и отрыва от фактов он использует нейтральные вводные конструкции: «иными словами», «другими словами» и т.д.

Непредвзятое изложение информации встречается в обобщающей технике, когда посредник воспроизводит высказывания в усеченном, обобщенном виде и кратко формулирует наиболее важные («ваши основные мысли...», «так...») и в технике развития мыслей, 
когда он выводит логическое следствие из слов собеседника («если исходить из того, что вы сказали...», «а вы хотели бы...»). Здесь нейтральность также выражается в высказывании, не имеющем эмоций и собственных интерпретаций.

Таким образом, мы можем видеть, что при разрешении споров посреднику, для эффективного урегулирования конфликта приходится прибегать к определенным способам речевой коммуникации, а также применять некоторые тактические приемы. Правильное и последовательное коммуникативное взаимодействие в условиях разрешения конфликтной ситуации включает спокойствие, нейтральную лексику, уважительное обращение сторон друг другу.

В заключении хотелось бы отметить, что разрешение конфликтной ситуации в современных условиях развития общества, либо урегулирование и благоприятный исход уже сложившейся коммуникативной конфликтной ситуации остается важным звеном в развитии нашего общества. Поэтому необходимо основательно исследовать и изучать причины возникновения юридических конфликтов, а также направить все силы на поиск средств их урегулирования и предотвращения.

\section{ЛИТЕРАТУРА}

1. Киндеркнехт А.С., Яковлева Ю.А. Вербальные и невербальные средства выражения нейтральности в коммуникативном поведении медиатора // Научный диалог. - 2020.— № 3.- - С. 82-95.

2. Миронов Е.А. Диалектика взаимодействия: сотрудничество и конфликт // Вестник Санкт-Петербургского университета. Серия 16. Психология. Педагогика. - 2012. - № 3.- С. 8-14.

3. Парфенов А.В. 0 роли ограничений и уступок в формировании стратегии поведения в конфликтной ситуации (на примере правового компромисса) // Юридическая техника. — 2018. — № 12.—C. 270-275.

4. Романенко М.А. Альтернативные формы разрешения правовых конфликтов в сфере прав человека и гражданина: автореферат дис. ... кандидата юридических наук. - Саратов, 2008. - 18 с.

(c) Усманова Елена Фанильевна (Usmanowa_ef@rambler.ru ), Малышкин Павел Викторович.

Журнал «Современная наука: актуальные проблемы теории и практики»

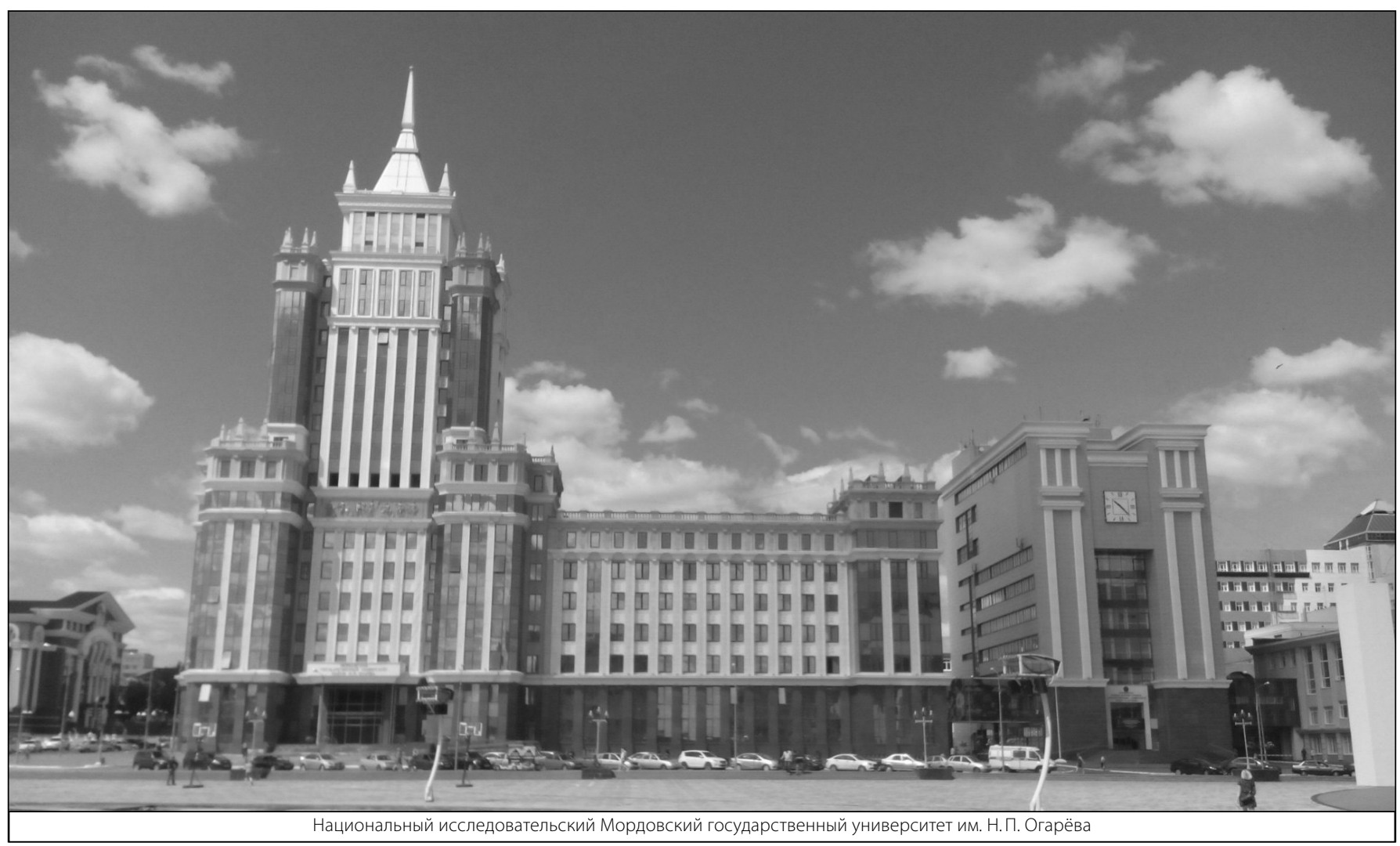

